\title{
Mitochondrial Dysfunctions in Patients with Migraine
}

\author{
R. Alloush', M. Haroun1, A. Shalash1, H. El-Fawal'2, M. Hamdy ${ }^{\text {* }}$ \\ ${ }^{1}$ Department of Neurology and Psychiatry, Faculty of Medicine, Ain Shams University, Cairo, Egypt \\ ${ }^{2}$ School of Sciences and Engineering, American University in Cairo, Cairo, Egypt \\ Email: *mohamedhamdy_neuro2007@yahoo.com
}

How to cite this paper: Alloush, R., Haroun, M., Shalash, A., El-Fawal, H. and Hamdy, M. (2019) Mitochondrial Dysfunctions in Patients with Migraine. Neuroscience \& Medicine, 10, 339-353.

https://doi.org/10.4236/nm.2019.104025

Received: September 13, 2019

Accepted: October 9, 2019

Published: October 12, 2019

Copyright () 2019 by author(s) and Scientific Research Publishing Inc. This work is licensed under the Creative Commons Attribution-NonCommercial International License (CC BY-NC 4.0). http://creativecommons.org/licenses/by-nc/4.0/

\begin{abstract}
Study Objectives: Migraine is a complex neurovascular disease and is believed to be due to a mixture of genetic and environmental factors. Study design: This was a cross-sectional observational prospective hospital based study conducted on 100 participants. They were divided into two groups; Group A: 50 migrainous patients according to the criteria of the International Classification of Headache Disorders and Group B: 50 healthy subjects both groups were age and sex matched. All subjects underwent a full neurological and psychiatric examination. Full headache evaluation sheet used in headache outpatient clinic in Ain Shams University Hospitals and HIT- $6^{\text {TM }}$ Headache Impact Test was used. Assay of serum level of N-acetyl-aspartate (NAA) as mitochondrial function marker was done. Results: There was no significant difference between both groups regarding gender, age or age group, marital state, education, residence and special habits. However, there was a statistical significant difference as regards family history of migraine more in patient group. In this study, serum NAA levels in migraine patients were significantly lower than in healthy controls. Decreased NAA level is generally believed to be a sign of reduced neuronal and glial mitochondrial function. Also, migraine with aura patients showed lower NAA levels when compared to migraine without aura subtypes. However, there was no significant correlation was found between NAA serum levels, and gender, age at onset, age group, type of aura, duration of the illness, type of onset of pain, frequent site of pain, time to max severity, severity of attack, and daily functions (social life, work, psychological wellbeing, sleep and cognition). Conclusions: Findings of this study indicate that NAA in serum may be a marker for neuronal dysfunction predisposing to migraine, probably related to the reduced mitochondria function.
\end{abstract}

\section{Keywords}

Migraine, Migraine with Aura, Migraine without Aura, Mitochondrial Function 
Marker, N-Acetyl-Aspartate (NAA), Magnetic Resonance Spectroscopy (MRS) and Liquid Chromatography-Mass Spectrometry (LC/MS)

\section{Introduction}

Migraine is a common, disabling, primary headache disorder, with episodic manifestations that affect women three times more than men [1]. Migraine is characterized by recurrent and often unilateral, vascular throbbing head pain and additional symptoms which can include nausea, emesis, photophobia, phonophobia. Other symptoms may include visual and sensory disturbances [2]. Lifetime prevalence of migraine is 3.38/100 in upper Egypt [3]. Subcortical structures; brainstem, hypothalamus and thalamus, are involved in the generation of migraine attacks. Neuronal hyperexcitability and trigemino-vascular activation are regarded to play an important role in migraine pathogenesis. The brainstem activates the trigemino-vascular system, which then stimulates perivascular trigeminal sensory afferent nerves with release of vasoactive neuropeptides, resulting in vasodilation and transduction of central nociceptive information [2].

The pathophysiology is largely unidentified despite excessive research and intense of interest because of the high prevalence and socioeconomic impact [1]. Many factors such as genetic background, nitric oxide hypersensitivity, lack of cortical habituation, and a disturbed energy metabolism may determine the migraine threshold [4]. The primary function of mitochondria is to produce ATP via the electron transport chain. Patients with migraine may have variants in nuclear genes involved in mitochondrial function or have particular haplotypes, polymorphisms, or mitochondrial double stranded deoxyribonucleic acid mutations [5]. Alteration in the brain excitability in migraine has been hypothesized, based on genetic mutations and/or polymorphisms of chromosomes [6]. A mitochondrial defect may reduce the threshold for migraine attacks by several mechanisms. Many magnetic resonance spectroscopy (MRS) studies have been performed in migraine patients and showed an interictal energy disturbance in the brain of migraine patients [7]. This may be due to dysfunction of metabolism of neurons. Neurons are the only source of $\mathrm{N}$-acetyl-aspartate (NAA). This molecule, which assesses neuronal integrity, leaves central nervous system through astrocytes and then it is reversed into circulation and excreted by kidney in urine samples [8]. The NAA is considered a marker of axonal integrity. It is synthesized and located prevalently in mitochondria of neurons and in fact it has been taken as a marker of mitochondrial functioning [9]. Prophylactic pharmacotherapy for migraine headaches is less than satisfactory, due to the lack of pathogenesis, the poor efficacy and debilitating adverse effects [10]. Identification of alterations of mitochondrial functions holds promise for better understanding of migraine pathogenesis, and may help in developing new strategies for prevention and treatment of migraine. In the current study, the aim is to explore the 
alterations of mitochondrial functions in migraine.

\section{Subject and Methods}

\subsection{Study Subject}

This was a cross sectional observational prospective hospital based study (simple random sampling) conducted on 100 participants from the outpatient clinics of Neurology, and Psychiatry in Ain Shams University Hospitals. They were selected from June 2018 till December 2018. The inclusion criteria were a diagnosis of migraine according to the criteria of the International Classification of Headache Disorders [11] with age18 years old and above. Exclusion criteria for patients and controls were the presence of general medical or neurological and psychiatric disorders, or history of medications that may cause headache as nitrates drugs. They were divided into two groups; Group A: 50 migrainous patients and Group B: 50 healthy subjects and are age and sex matched with the study group.

All subjects underwent a full neurological and psychiatric examination for each subject as migraine is a clinical diagnosis. All the patients were kept on their prophylactic therapy. The following was done; Full headache evaluation sheet used in headache outpatient clinic in Ain Shams University Hospitals, and HIT- $6^{\text {Tix }}$ Headache Impact Test. HIT is a tool used to measure the impact of headaches on patient ability to function on the job, at school, at home and in social situations [12].

Mitochondrial functions markers; serum level of NAA may be considered a useful marker of neuronal functioning. Venous blood samples were drawn from the antecubital vein in the morning hours one week after the last migraine attack. Plasma was separated from blood samples into plain biochemistry tubes by centrifugation at $3000 \mathrm{rpm}$ for $5 \mathrm{~min}$ at $4^{\circ} \mathrm{C}$. Plasma samples were stored at $-80^{\circ} \mathrm{C}$. Quantification of NAA was achieved by the standard addition approach and analysis was performed with Liquid chromatography-mass spectrometry (LC/MS) technique [13]. Liquid Chromatography with tandem mass spectrometry (LC-MS/MS) system and operating conditions NAA detection and analysis was performed on Agilent 1100 Series LC coupled to a mass selective detector (MSD) Ion Trap XCT mass spectrometer. A Shim-pack VP-ODS C18 $(150 \times 2.1$ $\mathrm{mm}$ i.d., $5 \mu \mathrm{m}$ ) was used for analyzing NAA from other compounds in the sample. The mobile phase was a mixture of acetonitrile (HPLC grade, 100\%) and water $(1: 9 \mathrm{v} / \mathrm{v})$ containing $0.1 \%$ formic acid at a flow rate of $0.20 \mathrm{ml} / \mathrm{min}$. The Ion Trap was operated with an orthogonal electrospray source in negative ion mode using a selective ion monitoring. For NAA, the ion transitions as 174Y88, $174 \mathrm{Y} 58$ and $174 \mathrm{Y} 130$ were monitored, with the $\mathrm{CDL}$ and heater block temperature was $250^{\circ} \mathrm{C}$ and $200^{\circ} \mathrm{C}$, the CDL and detection voltage was $25 \mathrm{~V}$ and $185 \mathrm{kV}$, atomizing gas and drying gas flow rate was $1.5 \mathrm{~L} / \mathrm{min}$ and $2.0 \mathrm{~L} / \mathrm{min}$ [14]. Experimental procedures were previously approved by the Ethical Committee for Human Research at the faculty of medicine Ain Shams University. 


\subsection{Statistical Analysis}

Recorded data were analyzed using the statistical package for social sciences, version 20.0 (SPSS Inc., Chicago, Illinois, USA). Quantitative data were expressed as mean \pm standard deviation (SD). Qualitative data were expressed as frequency and percentage. The following tests were done:

A one-way analysis of variance (ANOVA) when comparing between more than two means; Post Hoc test: Least Significant Difference (LSD) was used for multiple comparisons between different variables; Chi-square $\left(\chi^{2}\right)$ test of significance was used in order to compare proportions between qualitative parameters. The confidence interval was set to $95 \%$ and the margin of error accepted was set to $5 \%$. So, the $\mathrm{p}$-value was considered significant if $\mathrm{p}$-value $<0.05$.

\section{Results}

\subsection{Demographic Features in the Studied Groups}

Migraineurs and control group showed similar demographic profiles, with no statistically significant difference as regards gender, age or age group, marital state, education, residence and special habits between both groups. However, there was statistically significant difference as regards family history of migraine more in group A as $(\mathrm{p}=0.009)$ (Table 1$)$.

\subsection{Clinical Characteristic of Headache}

As regards clinical features of the patients group; migraine with aura was found in $7(14 \%)$ and migraine without aura was found in 43 (86\%). Duration of illness of 0 - 5 years was found in 18 (36\%), 5 - 10 years was found in $16(32 \%), 10-15$ years was found in $9(18 \%)$ and more than 15 years was found in 7 (14\%). Unilateral headache was present in $12(24 \%)$, bilateral in $22(44 \%)$ and diffuse in 16 (32\%). The most frequent location of headache was frontal in $33(66 \%)$, temporal in $32(64 \%)$, occipital in $7(14 \%)$, vertex in $21(42 \%)$ and orbital or retro orbital in $8(16 \%)$. Sudden onset of pain was present in $12(24 \%)$ but gradual onset was present in $38(76 \%)$. Time to reach maximum intensity was in seconds in 3 (6\%), minutes in $5(10 \%)$ and in hours in $42(84 \%)$. Character of headache was Throbbing in 38 (76\%), Band-like tightening in $6(12 \%)$, Exploding in $15(30 \%)$, Stabbing in 2 (4\%), Lancinating in 15 (30) and Burning in 11 (22\%). Frequency of headache: per day in 15 (30\%), per week in $23(46 \%)$ and per month in 12 (24\%). Attack duration without treatment was $<2$ hrs in 4 (8\%), $2-4 \mathrm{hrs}$ in 13 (26\%), $>4$ hrs in $28(56 \%)$ and days in $6(12 \%)$. Severity of headache attack was mild in $5(10 \%)$, moderate in $27(54 \%)$ and severe in 18 (36\%). Associated symptoms were photophobia and phonophobia in $29(58 \%)$, nausea and vomiting in $13(26 \%)$, vertigo in $25(50 \%)$, paresthesia in $3(6 \%)$ and lacrimation and conjunctival injection in 1 (2\%) (Table 2).

Migraine with aura was present in 3 males and 4 females. Migraine without aura was present in 17 males and 26 females (Table 3 ). 


\subsection{Comparison between Mean Values of Serum Level of NAA in the Two Groups}

As regards serum level of NAA in the two groups, there was statistically significant difference with low serum level of NAA in the migraine group as $p=0.001$ (Table 4).

Table 1. Demographic features in the studied groups.

\begin{tabular}{|c|c|c|c|}
\hline & $\begin{array}{l}\text { Group A patients } \\
\qquad(\mathrm{n}=50)\end{array}$ & $\begin{array}{c}\text { Group B control } \\
(n=50)\end{array}$ & $\mathrm{p}$-value \\
\hline \multicolumn{4}{|l|}{ Gender } \\
\hline Male & $20(40 \%)$ & $21(42 \%)$ & \multirow[t]{2}{*}{0.839} \\
\hline Female & $30(60 \%)$ & $29(58 \%)$ & \\
\hline \multicolumn{4}{|l|}{ Age } \\
\hline Range; years & $19-61$ & $19-60$ & \multirow[t]{2}{*}{0.501} \\
\hline Mean $\pm(S D)$; years & $34.54 \pm 8.94$ & $33.38 \pm 8.23$ & \\
\hline \multicolumn{4}{|l|}{ Age Group } \\
\hline $18-30$ years & $17(34.0 \%)$ & $20(40.0 \%)$ & \multirow{3}{*}{0.793} \\
\hline $30-40$ years & $22(44.0 \%)$ & $19(38.0 \%)$ & \\
\hline$>40$ years & $11(22.0 \%)$ & $11(22.0 \%)$ & \\
\hline \multicolumn{4}{|l|}{ Age at onset } \\
\hline$<20$ years & $11(22.0 \%)$ & & \\
\hline$\geq 20-\leq 40$ years & $36(72.0 \%)$ & & \\
\hline$>40$ years & $3(6.0 \%)$ & & \\
\hline \multicolumn{4}{|l|}{ Marital State } \\
\hline Married & $32(64.0 \%)$ & $35(70.0 \%)$ & \multirow{4}{*}{0.921} \\
\hline Single & $14(28.0 \%)$ & $12(24.0 \%)$ & \\
\hline Widow & $1(2.0 \%)$ & $1(2.0 \%)$ & \\
\hline Divorced & $3(6.0 \%)$ & $2(4.0 \%)$ & \\
\hline \multicolumn{4}{|l|}{ Education } \\
\hline Illiterate & $7(14.0 \%)$ & $9(18.0 \%)$ & \multirow{3}{*}{0.858} \\
\hline Reads and writes & $6(12.0 \%)$ & $6(12.0 \%)$ & \\
\hline Graduated & $37(74.0 \%)$ & $35(70.0 \%)$ & \\
\hline \multicolumn{4}{|l|}{ Residence } \\
\hline Urban & $37(74.0 \%)$ & $36(72.0 \%)$ & \multirow{2}{*}{0.822} \\
\hline Rural & $13(26.0 \%)$ & $14(28.0 \%)$ & \\
\hline \multicolumn{4}{|l|}{ Special habits } \\
\hline 1-Smoking & $18(36.0 \%)$ & $26(52.0 \%)$ & \multirow{3}{*}{0.150} \\
\hline 2-Illicit drugs & $6(12.0 \%)$ & $2(4.0 \%)$ & \\
\hline $3-\mathrm{No}$ & $26(52.0 \%)$ & $22(44.0 \%)$ & \\
\hline \multicolumn{4}{|c|}{ Family history of similar condition } \\
\hline Yes & $34(68.0 \%)$ & $21(42.0 \%)$ & \multirow[t]{2}{*}{$0.009^{*}$} \\
\hline No & $16(32.0 \%)$ & $29(58.0 \%)$ & \\
\hline
\end{tabular}


Table 2. Clinical characteristic of headache.

\begin{tabular}{|c|c|c|}
\hline & $\mathrm{N}$. & $\%$ \\
\hline \multicolumn{3}{|l|}{ Types of migraine } \\
\hline With aura & 7 & 14 \\
\hline Without aura & 43 & 86 \\
\hline \multicolumn{3}{|l|}{ Duration of illness } \\
\hline $0-5$ years & 18 & 36 \\
\hline $5-10$ years & 16 & 32 \\
\hline $10-15$ years & 9 & 18 \\
\hline More than 15 years & 7 & 14 \\
\hline \multicolumn{3}{|l|}{ Most frequent site } \\
\hline Unilateral & 12 & 24 \\
\hline Bilateral & 22 & 44 \\
\hline Diffuse & 16 & 32 \\
\hline \multicolumn{3}{|l|}{ Most frequent location } \\
\hline Frontal & 33 & 66 \\
\hline Temporal & 32 & 64 \\
\hline Occipital & 7 & 14 \\
\hline Vertex & 21 & 42 \\
\hline Orbital or retro-orbital & 8 & 16 \\
\hline \multicolumn{3}{|l|}{ Type of pain onset } \\
\hline Sudden & 12 & 24 \\
\hline Gradual & 38 & 76 \\
\hline \multicolumn{3}{|c|}{ Time to reach maximum intensity: } \\
\hline Seconds & 3 & 6 \\
\hline Mints & 5 & 10 \\
\hline Hours & 42 & 84 \\
\hline \multicolumn{3}{|l|}{ Character } \\
\hline Throbbing & 38 & 76 \\
\hline Band-like tightening & 6 & 12 \\
\hline Exploding & 15 & 30 \\
\hline Stabbing & 2 & 4 \\
\hline Lancinating & 15 & 30 \\
\hline Burning & 11 & 22 \\
\hline \multicolumn{3}{|l|}{ Frequency } \\
\hline Per day & 15 & 30 \\
\hline Per week & 23 & 46 \\
\hline Per month & 12 & 24 \\
\hline \multicolumn{3}{|c|}{ Attack duration without treatment: } \\
\hline$<2 \mathrm{hrs}$ & 4 & 8 \\
\hline $2-4 \mathrm{hrs}$ & 13 & 26 \\
\hline$>4 \mathrm{hrs}$ & 28 & 56 \\
\hline Days & 6 & 12 \\
\hline
\end{tabular}




\begin{tabular}{ccc}
\hline Severity: & & \\
Mild & 5 & 10 \\
Moderate & 27 & 54 \\
Severe & 18 & 36 \\
\hline Associated symptoms: & & \\
Photophobia \& Phonophobia & 29 & 58 \\
Nausea \& Vomiting & 13 & 26 \\
Vertigo & 25 & 50 \\
Paresthesia & 3 & 6 \\
Lacrimation/conjunctival injection & 1 & 2 \\
\hline
\end{tabular}

Table 3. Frequency of migraine subtypes among the studied population.

\begin{tabular}{ccccc}
\hline & Male & Female & Total & $\%$ \\
\hline Migraine with aura & 3 & 4 & 7 & 14 \\
Migraine without aura & 17 & 26 & 43 & 86
\end{tabular}

Table 4. Comparison between mean values of serum level of NAA in the two studied groups.

\begin{tabular}{cccc}
\hline & $\begin{array}{c}\text { Group A } \\
\text { Patients }(\mathrm{n}=50)\end{array}$ & $\begin{array}{c}\text { Group B } \\
\text { Control }(\mathrm{n}=50)\end{array}$ & p-value \\
\hline NAA & $0.030 \pm 0.008$ & $0.066 \pm 0.029$ & $0.001^{*}$ \\
\hline
\end{tabular}

${ }^{*} \mathrm{p} \leq 0.05=$ significant.

\subsection{Correlation between Values of NAA Serum Level and Clinical Characteristic of Patient Group}

There was no statistical significant difference As regards serum level of NAA in relation to age and age groups ( $18-30$ yrs., $30-40$ yrs. and $>40$ yrs.) as $p=0.256$ $\& \mathrm{p}=0.235$ (Table 5).

There was no statistically significant difference as regards serum level of NAA in relation to gender of patients as p-value $=0.403$ and to age of onset of headache: ( $<20$ yrs., $>20-40$ yrs. and $>40$ yrs.) as $p=0.555$ (Table 6).

There were statistically significant differences as regards serum level of NAA in relation to type of migraine with low NAA serum level in migraine with aura as $(\mathrm{p}=0.009)$. However, there were no statistically significant differences as regards serum level of NAA in relation to type of migraine aura, as $\mathrm{p}=0.437$ (Table 7).

There were no statistically significant differences as regards serum level of NAA in relation to migraine duration groups, as $(p=0.441)$. Also, there were no statistically significant differences as regards serum level of NAA in relation to frequent site of migraine attack $(\mathrm{p}=0.945)$ (Table 8).

There were no statistically significant differences as regards serum level of NAA in relation to onset of pain of the migrainous attack, $(p=0.295)$ and time to max severity of the migraine attack $(\mathrm{p}=0.535)$ (Table 9$)$. 
Table 5. Correlation between values of NAA serum level in relation to age and age groups.

\begin{tabular}{ccccc}
\hline & No. (\%) & Mean \pm SD & Test of sig. & p-value \\
\hline Age & & $34.54 \pm 8.94$ & $\mathrm{r}=0.171$ & 0.236 \\
Age group & & & & \\
$18-30$ yrs. & $17(34 \%)$ & $0.028 \pm 0.009$ & $\chi^{2}=2.726$ & 0.256 \\
$30-40$ yrs. & $22(44 \%)$ & $0.032 \pm 0.008$ & - & - \\
$>40$ yrs. & $11(22 \%)$ & $0.032 \pm 0.008$ & - & - \\
\hline
\end{tabular}

Table 6. Correlation between values of NAA serum level in relation to gender and age of onset of headache.

\begin{tabular}{ccccc}
\hline & No. $(\%)$ & Mean \pm SD & Test of sig. & p-value \\
\hline $\begin{array}{c}\text { Gender } \\
\text { Female }\end{array}$ & $30(60 \%)$ & $0.030 \pm 0.009$ & $\mathrm{t}=0.843$ & 0.403 \\
$\begin{array}{c}\text { Male } \\
\text { Age of onset }\end{array}$ & $20(40 \%)$ & $0.032 \pm 0.007$ & & \\
$<20$ yrs. & $11(22 \%)$ & $0.030 \pm 0.008$ & $\chi^{2}=1.176$ & 0.555 \\
$\geq 20-40$ yrs. & $36(72 \%)$ & $0.030 \pm 0.009$ & & \\
$>40$ yrs. & $3(6 \%)$ & $0.036 \pm 0.011$ & & \\
\hline
\end{tabular}

Table 7. Correlation between values of NAA serum level in relation to type of migraine and type of aura.

\begin{tabular}{ccccc}
\hline & No. (\%) & Mean \pm SD & Test of sig. & p-value \\
\hline $\begin{array}{c}\text { Type of migraine } \\
\text { With aura }\end{array}$ & $7(14 \%)$ & $0.022 \pm 0.009$ & $\mathrm{Z}=-2.604$ & $0.009^{*}$ \\
Without aura & $43(86 \%)$ & $0.032 \pm 0.008$ & & \\
Type of aura & & & & \\
Visual & $6(12 \%)$ & $0.008 \pm 0.003$ & $\mathrm{Z}=-0.778$ & 0.437 \\
Sensory & $3(6 \%)$ & $0.006 \pm 0.003$ & & \\
\hline
\end{tabular}

${ }^{*} \mathrm{p} \leq 0.05=$ significant.

Table 8. Correlation between values of NAA serum level in relation to migraine duration and frequent site of migraine attack.

\begin{tabular}{ccccc}
\hline & No. $(\%)$ & Mean \pm SD & Test of sig. & p-value \\
\hline Migraine duration & & & & \\
$0-5$ years & $18(36 \%)$ & $0.028 \pm 0.007$ & $\chi^{2}=2.693$ & 0.441 \\
$5-10$ years & $16(32 \%)$ & $0.033 \pm 0.010$ & & \\
$10-15$ years & $9(18 \%)$ & $0.030 \pm 0.009$ & & \\
More than 15 years & $7(14 \%)$ & $0.032 \pm 0.008$ & & \\
Frequent site & & & & \\
Unilateral & $12(24 \%)$ & $0.030 \pm 0.006$ & $\chi^{2}=0.113$ \\
Bilateral & $22(44 \%)$ & $0.031 \pm 0.009$ & & \\
Diffuse & $16(32 \%)$ & $0.030 \pm 0.010$ & & \\
\hline
\end{tabular}


There were no statistically significant differences as regards serum level of NAA in relation to severity of the migrainous attack; mild, moderate or severe, $(\mathrm{p}=0.716)$. Also, There were no statistically significant differences as regards serum level of NAA in relation to daily functions (Your social life, Your work, Psychological wellbeing, Sleep and Cognition (memory \& concentration) with increased functional disability with low NAA $(\mathrm{p}=0.528)($ Table 10$)$.

\section{Discussion}

Migraine is a complex neurovascular disorder, involving complex genetics, multiple neurotransmitter systems, and multiple cortical and subcortical structures of the brain [15]. Migraine is a disorder of neurovascular origin, which causes remain partly unknown. Altered brain excitability has been supposed, based on genetic mutations and/or polymorphisms of chromosomes, yet to be determined, which regulate the metabolism of neuronal mitochondrial energy, neurotransmitters and ion canals of the CNS [16]. The aim of this study was to explore the alterations of mitochondrial functions in migraine by assay of serum level of NAA.

Table 9. Correlation between values of NAA serum level in relation to onset of pain of and time to max severity of the migraine attack.

\begin{tabular}{ccccc}
\hline & No. (\%) & Mean \pm SD & Test of sig. & p-value \\
\hline Pain onset & & & & \\
Sudden & $12(24 \%)$ & $0.033 \pm 0.009$ & $\mathrm{Z}=-1.046$ & 0.295 \\
Gradual & $38(76 \%)$ & $0.030 \pm 0.008$ & & \\
Time to max severity & & & & \\
Seconds & $3(6 \%)$ & $0.036 \pm 0.020$ & $\chi^{2}=1.252$ & \\
Minutes & $42(84 \%)$ & $0.030 \pm 0.008$ & & \\
Hours & $5(10 \%)$ & $0.033 \pm 0.007$ & & \\
\hline
\end{tabular}

Table 10. Correlation between values of NAA serum level in relation to severity of the migraine attack (pain).

\begin{tabular}{|c|c|c|c|c|}
\hline & No. (\%) & Mean \pm SD & Test of sig. & p-value \\
\hline \multicolumn{5}{|c|}{ Severity of attack } \\
\hline Mild & $5(10 \%)$ & $0.035 \pm 0.013$ & $\chi^{2}=0.669$ & 0.716 \\
\hline Moderate & 27 (54\%) & $0.030 \pm 0.008$ & & \\
\hline Severe & $18(36 \%)$ & $0.029 \pm 0.007$ & & \\
\hline \multicolumn{5}{|c|}{ Functions affected } \\
\hline Mild & $2(4 \%)$ & $0.038 \pm 0.014$ & $\chi^{2}=0.252$ & 0.528 \\
\hline Moderate & $16(32 \%)$ & $0.033 \pm 0.009$ & & \\
\hline Severe & $16(52 \%)$ & $0.031 \pm 0.007$ & & \\
\hline Extreme & $8(16 \%)$ & $0.034 \pm 0.006$ & & \\
\hline
\end{tabular}


In this study there was no significant difference between the two groups regarding as regards gender, age or age group, marital state, education, residence and special habits between both groups. However there was statistical significant difference as regards family history of migraine more in migrainous group. Similar findings were reported by Pelzer et al. (2019) as there are stronger family histories of migraine in migrainous patients [17].

As regards clinical features of the patients group; migraine without aura was found in (86\%). Unilateral headache was present in (24\%), bilateral in $(44 \%)$ and diffuse in (32\%). The most frequent location of headache was frontal in (66\%). Character of headache was throbbing in $(76 \%)$. Severity of headache attack was mild in (10\%), moderate in (54\%) and severe in (36\%). Associated symptoms were photophobia and phonophobia in (58\%), nausea and vomiting in (26\%) and vertigo in (50\%). Similar findings were reported by De Rijk et al. (2018) in their study [18]. As, they found $13.8 \%$ of patients had migraine with aura. Unilateral pain location was reported by $58.6 \%$ of patients and the throbbing type of pain was present in $50.2 \%$ of their group. Photo- and phonophobia were observed in $77.4 \%$ and $79.5 \%$ of patients.

In this study, serum NAA levels in migraine patients were significantly lower than in healthy controls. This result seems to confirm previous findings by De Tommaso et al. (2012) founded that the NAA levels were significantly decreased in migraine group $(0.065 \pm 0.019 \mathrm{~mol} / \mathrm{L})$, compared with both tension-type headache patients $(0.078 \pm 0.016 \mathrm{~mol} / \mathrm{L})$ and controls $(0.085 \pm 0.013 \mathrm{~mol} / \mathrm{L})$ [19] . Also, Sarchielli et al. (2005), described reduced brain NAA signal in migraine patients examining $1 \mathrm{H}-\mathrm{MRS}$ during cortical activation induced by photic stimulation [20]. The main result of photic stimulation in patients with migraine with aura was the more consistent decrease $(-14.61 \%)$ of the NAA signal, which is significantly greater than that found in migraine patients without aura and control subjects. In addition to that, many studies reported decreased NAA in the occipital lobe and thalamus in migraine with and without aura and in the cerebellum of sporadic and familiar hemiplegic migraine detected by $1 \mathrm{H}-\mathrm{MRS}$ [7] [21] [22] [23].

Decreased NAA level is generally believed to indicate a neuronal loss [9]. Mitochondrial dysfunction has been identified as one potential cause of epileptic seizures and altered brain excitability, and in this sense the measure of serum NAA in epileptic patients and more specifically in mitochondrial encephalomyopathy, lactic acidosis, and stroke-like episodes (MELAS) and myoclonic epilepsy with ragged red fibers (MERFF) syndromes would confirm the origin of the low NAA levels [24]. However, based on these studies reporting reversibility of the NAA levels in many diseases, it has been proposed that the NAA decrease might indicate a subsided mitochondrial dysfunction, if accepted that the synthesis is mitochondrial, thus contributing to the abnormal energy metabolism [25]. The NAA serum reduction may be nonspecific finding; however, following the reason that it may be a sign of reduced neuronal and glial mitochondria 
function, the hypothesis of deficient energy metabolism may be supposed for both types of migraine [8] [26]. As energy failure in neurons and astrocytes, may triggering migraine mechanisms [27].

Moreover, cerebral mitochondrial injury seems to be related to cortical spreading depression, so assuming that this neuronal phenomenon may precede any form of migraine, independently from the perception of aura symptoms, the NAA reduction may be the consequence of the migraine episodes repetition [28].

In this study migraine with aura patients showed lower NAA levels when compared to migraine without aura subtypes. This result confirms previous findings by De Tommaso et al. (2012) who described reduced brain NAA signal in migraine with aura patients when compared to all the other headache subtypes, including migraine without aura and chronic migraine [19]. Also, Sarchielli et al. (2005) reported that the NAA reduction detected by $1 \mathrm{H}-\mathrm{MRS}$ was specially observed in migraine with aura patients under the cortical activation induced by photic stimulation, while the NAA reduction observed in migraine without aura was only slightly more evident than in controls [20]. The presence of less efficient mitochondrial functioning in migraine with aura patients compared with migraine without aura patients and controls and that the reversible loss of NAA during visual stimulation may be due to a redistribution of NAA from the intra to the extracellular space, which would result in a variation in chemical environment that may alter its magnetic resonance visibility [29]. Also, the low serum NAA is a sign of neuronal dysfunction predisposing to migraine, with a more evident phenotypic expression in patients experiencing aura symptoms.

In this study, in the migraine group, no significant correlation was found between NAA serum levels, and type of onset of pain, frequent site of pain, time to max severity, severity of attack, duration of migraine attack and daily functions (social life, work, psychological wellbeing, sleep and cognition). Similar findings were reported by De Tommaso et al. (2012) as they found in their migraine group patients; no significant correlation was found between NAA serum levels, and frequency, allodynia and interval from the last and the next attack [19]. The low NAA in the serum may be a sign of neuronal dysfunction predisposing to migraine, probably based on reduced mitochondria function.

In this study, in the migraine group, no significant correlation was found between NAA serum levels, and age at onset, age group, sex, type of aura and duration of the illness. In agreement with previous results of De Tommaso et al. (2012) whom found that the low NAA serum levels were independent of possible confounding factors such as age and sex [19]. This decrease could be a consequence of an energetic problem linked to mitochondria, perhaps based on an enzyme deficit, so the molecule is unable to exit from mitochondria to serum without relation to age or sex. However Shannon et al. (2016) in their study, found an age-related decline of NAA serum levels in healthy subjects [30]. As, they demonstrated that NAA serum levels did not differ between genders, whe- 
reas they were significantly lower in older subjects ( $>60$ years) than those in younger groups. This can be considered as a physiological event, as with aging, the reduced serum NAA might be a result of a reduced NAA synthesis, excretion and protein binding secondary to age-related neuronal energetic impairment [31]. This discrepancy can be attributed to both small number of the sample in this study and/or the variable clinical inclusion criteria used and the variation in applied methodology.

However, the lack of correlation between NAA levels, and frequency of migraine, site of pain, onset of pain, and pain severity detected in migraine group in present study could indicate that low serum NAA is not related to central mechanisms of pain processing, but to neuronal abnormalities which may specifically predispose to migraine [32].

Reduced levels of NAA could be associated with an increased risk of stroke and migraine progression [33]. The finding of a cerebral protective effect of acetylsalicylic acid (in terms of a reduction of the risk of ischemic stroke, in the dose of $100 \mathrm{mg}$ and the long-term risk of cardiovascular and cerebrovascular events associated with migraine headache, raise some doubts about the complete benignity of migraine [22] [34]. A migraineur subject, even with a low absolute cardiovascular risk; female, age under 45 years, may in fact, be at a higher relative risk due to the presence of other factors, such as aura component, smoking and the use of oral contraceptives [35]. The evaluation of serum levels of NAA is crucial in the control of the conventional risk factors. In addition, the therapeutic metabolite monitoring of NAA may be helpful in the assessment of the chronicization process [36].

This study can speculate that a biomarker in serum cannot actually localize the specific affected brain region, but it generally reflects damage, most probably to neuronal mitochondria.

\section{Limitations and Strengths}

This study has some limitations which have to be taken into consideration. First, the sample size was relatively small, resulting in low statistical power for detecting significant differences between subgroups. Second this study was unable to detect NAA Cerebrospinal fluid (CSF) levels for ethical problem, so it is possible to postulate its lower levels in CSF too.

However, the strengths of this study was the correlation between the socio-demographic and clinical characteristic of migraine and NAA serum level and this study can recommend the use serum NAA as a biomarker for migraine patients.

\section{Conclusions}

In this study, serum NAA levels in migraine patients were significantly lower than in healthy controls. The NAA levels were reduced in both types of migraine, though patients experiencing aura symptoms were characterized by the 
lowest serum NAA.

The NAA reduction in the serum is a quite unspecific finding; however, following the reason that it may be a sign of reduced neuronal and glial mitochondria function, the hypothesis of deficient energy metabolism may be supposed for both subtypes of migraine.

Serum NAA can be used as a simple biomarker for migraine. Furthermore, new techniques are crucial for clinicians in order to further elucidate pathophysiological mechanisms underlying this complex and often disabling disease and to provide new therapeutical approaches for migraine patients.

\section{Conflicts of Interest}

The authors declare no conflicts of interest regarding the publication of this paper.

\section{References}

[1] Edmeads, J. and Mackell, J.A. (2002) The Economic Impact of Migraine: An Analysis of Direct and Indirect Costs. Headache, 42, 501-509.

https://doi.org/10.1046/j.1526-4610.2002.04262.x

[2] Goadsby, P.J. (2003) Migraine: Diagnosis and Management. Internal Medicine Journal, 33, 436-442. https://doi.org/10.1046/j.1445-5994.2003.00453.x

[3] El-Tallawy, H.N., Farghaly, W.M., Mohamed, A., Abdelhamed, M.A., Badry, R., Rageh, T.A., et al. (2019) Prevalence of Migraine in Upper Egypt. The Egyptian Journal of Neurology, Psychiatry and Neurosurgery, 55, 20. https://doi.org/10.1186/s41983-019-0067-x

[4] Reyngoudt, H., Paemeleire, K., Descamps, B., De Deene, Y. and Achten, E. (2011) 31P-MRS Demonstrates a Reduction in High-Energy Phosphates in the Occipital Lobe of Migraine without Aura Patients. Cephalalgia, 31, 1243-1253. https://doi.org/10.1177/0333102410394675

[5] Sparaco, M., Feleppa, M., Lipton, R.B., Rapoport, A.M. and Bigal, M.E. (2006) Mitochondrial Dysfunction and Migraine: Evidence and Hypotheses. Cephalalgia, 26, 361-372. https://doi.org/10.1111/j.1468-2982.2005.01059.x

[6] Becerra, L., Veggeberg, R., Prescot, A., Jensen, J., Renshaw, P., Scrivani, S., Spieringsh, E., Bursteini, R. and Borsooka, D. (2016) A “Complex” of Brain Metabolites Distinguish Altered Chemistry in the Cingulate Cortex of Episodic Migraine Patients. NeuroImage: Clinical, 11, 588-594. https://doi.org/10.1016/j.nicl.2016.03.020

[7] Reyngoudt, H., Paemeleire, K., Dierickx, A., Descamps, B., Vandemaele, P., De Deene, Y. and Achten, E. (2011) Does Visual Cortex Lactate Increase Following Photic Stimulation in Migraine without Aura Patients? A Functional 1H-MRS Study. The Journal of Headache and Pain, 12, 295-302. https://doi.org/10.1007/s10194-011-0295-7

[8] Bates, T.E., Strangward, M., Keelan, J., Davey, G.P., Munro, P.M. and Clark, J.B. (1996) Inhibition of N-Acetylaspartate Production: Implications for $1 \mathrm{H}$ MRS Studies in Vivo. NeuroReport, 7, 1397-1400. https://doi.org/10.1097/00001756-199605310-00014

[9] Clark, J.B. (1998) N-Acetyl Aspartate: A Marker for Neuronal Loss or Mitochondrial Dysfunction. Developmental Neuroscience, 20, 271-276.

https://doi.org/10.1159/000017321 
[10] Kalra, A. and Elliott, D. (2007) Acute Migraine: Current Treatment and Emerging Therapies. Therapeutics and Clinical Risk Management, 3, 449-459.

[11] Headache Classification Committee of the International Headache Society (IHS) (2018) The International Classification of Headache Disorders, 3rd Edition. Cephalalgia, 38, 1-211. https://doi.org/10.1177/0333102417738202

[12] Kosinski, M., Bayliss, M.S., Bjorner, J.B., Ware, J.E., et al. (2003) A Six-Item Short-Form Survey for Measuring Headache Impact: The HIT-6. Quality of Life Research, 12, 963-974. https://doi.org/10.1023/A:1026119331193

[13] Ruggieri, M., Tortorella, C., Ceci, E., Paolicelli, D., Solfrizzi, V., Di Bitonto, G., Pica, C., Mastrapasqua, M., Livrea, P. and Trojano, M. (2011) Age-Related Changes of Serum N-Acetyl-Aspartate in Healthy Controls. Age Ageing, 40, 391-395. https://doi.org/10.1093/ageing/afr021

[14] Hu, L., Li, M., Hou, W., Zhou, J., Zhang, X., Yang, B., Tan, Y., Huang, J. and Tang, Z. (2016) Assessment of Plasma N-Acetyl Aspartic Acid by Liquid Chromatography-Mass Spectrometry in Patients with Alzheimer's Disease. International Journal of Clinical and Experimental Medicine, 9, 23568-23575.

[15] Reyngoudt, H., Achten, E. and Paemeleire, K. (2012) Magnetic Resonance Spectroscopy in Migraine: What Have We Learned So Far? Cephalalgia, 32, 845-859. https://doi.org/10.1177/0333102412452048

[16] Montagna, P. (2008) Migraine: A Genetic Disease? Neurological Sciences, 29, S47-S51. https://doi.org/10.1007/s10072-008-0886-5

[17] Pelzer, N., Louter, M., van Zwet, Nyholt, D., Ferrari, M., Maagdenberg, A., Haan, J. and Terwindt, G. (2019) Linking Migraine Frequency with Family History of Migraine. Cephalalgia, 39, 229-236. https://doi.org/10.1177/0333102418783295

[18] De Rijk, P., Resseguier, N. and Donnet, A. (2018) Headache Characteristics and Clinical Features of Elderly Migraine Patients. Headache, 58, 525-533. https://doi.org/10.1111/head.13247

[19] De Tommaso, M., Ceci, E., Pica, C., Trojano, M., Delussi, M., Franco, G., Livrea, P. and Ruggieri, M. (2012) Serum Levels of N-Acetyl-Aspartate in Migraine and Tension-Type Headache. The Journal of Headache and Pain, 13, 389-394. https://doi.org/10.1007/s10194-012-0448-3

[20] Sarchielli, P., Tarducci, R., Presciutti, O., Gobbi, G., Pelliccioli, G.P., Stipa, G., Alberti, A. and Capocchi, G. (2005) Functional 1H-MRS Findings in Migraine Patients with and without Aura Assessed Interictally. Neuroimage, 15, 1025-1031. https://doi.org/10.1016/j.neuroimage.2004.11.005

[21] Gu, T., Ma, X.X., Xu, Y.H., Xiu, J.J. and Li, C.F. (2008) Metabolite Concentration Ratios in Thalami of Patients with Migraine and Trigeminal Neuralgia Measured with 1H-MRS. Neurological Research, 30, 229-233. https://doi.org/10.1179/016164107X235473

[22] Mohamed, R.E., Aboelsafa, A.A. and Al-Malt, A.M. (2013) Interictal Alterations of Thalamic Metabolic Concentration Ratios in Migraine without Aura Detected by Proton Magnetic Resonance Spectroscopy. The Egyptian Journal of Radiology and Nuclear Medicine, 44, 859-870. https://doi.org/10.1016/j.ejrnm.2013.08.004

[23] Younis, S., Hougaard, A., Vestergaard, M., Larsson, H. and Ashina, M. (2017) Migraine and Magnetic Resonance Spectroscopy: A Systematic Review. Current Opinion in Neurology, 30, 246-262. https://doi.org/10.1097/WCO.0000000000000436

[24] Folbergrova, J. and Kunz, W.S. (2012) Mitochondrial Dysfunction in Epilepsy. Mitochondrion, 12, 35-40. https://doi.org/10.1016/j.mito.2011.04.004 
[25] Niu, F., Meng, H., Chang, L., Wu, H., Li, W., et al. (2017) Mitochondrial Dysfunction and Cerebral Metabolic Abnormalities in Patients with Mitochondrial Encephalomyopathy Subtypes: Evidence from Proton MR Spectroscopy and Muscle Biobsy. CNS Neuroscience and Therapeutics, 23, 8. https://doi.org/10.1111/cns.12714

[26] Lian, X.Y. and Stringer, J.L. (2004) Energy Failure in Astrocytes Increases the Vulnerability of Neurons to Spreading Depression. European Journal of Neuroscience, 19, 2446-2454. https://doi.org/10.1111/j.0953-816X.2004.03289.x

[27] Yorns, W.R. and Hardison, H.H. (2013) Mitochondrial Dysfunction in Migraine. Seminars in Pediatric Neurology, 20, 188-193. https://doi.org/10.1016/j.spen.2013.09.002

[28] Li, F., Qiu, E., Dong, Z., Liu, R., Wu, S. and Yu, S. (2011) Protection of Flunarizine on Cerebral Mitochondria Injury Induced by Cortical Spreading Depression under Hypoxic Conditions. The Journal of Headache and Pain, 12, 47-53. https://doi.org/10.1007/s10194-011-0300-1

[29] Taylor, D.L., Davies, S.E., Obrenovitch, T.P., Doheny, M.H., Patsalos, P.N., Clark, J. and Symon, L. (1995) Investigation into the Role of N-Acetylaspartate in Cerebral Osmoregulation. Journal of Neurochemistry, 65, 275-281. https://doi.org/10.1046/j.1471-4159.1995.65010275.x

[30] Shannon, R.J., Van der Heide, S., Carter, E.L., Jalloh, I., Menon, D.K., Hutchinson, P.J. and Carpenter, K. (2016) Extracellular N-Acetylaspartate in Human Traumatic Brain Injury. Journal of Neurotrauma, 33, 319-329. https://doi.org/10.1089/neu.2015.3950

[31] Pan, J.W. and Takahashi, K. (2005) Interdependence of N-Acetyl Aspartate and High-Energy Phosphates in Healthy Human Brain. Annals of Neurology, 57, 92-97. https://doi.org/10.1002/ana.20317

[32] Gustin, S.M., Peck, C.C., Wilcox, S.L., Nash, P.G., Murray, G.M. and Henderson, L.A. (2011) Different Pain, Different Brain: Thalamic Anatomy in Neuropathic and Non-Neuropathic Chronic Pain Syndromes. Journal of Neuroscience, 20, 5956-5964. https://doi.org/10.1523/JNEUROSCI.5980-10.2011

[33] Lionetto, L., Capi, M., Vignaroli, G., Negro, A. and Martelletti, P. (2012) Deciphering the Task of N-Acetyl Aspartate in Migraine. Expert Review of Neurotherapeutics, 12, 1057-1059. https://doi.org/10.1586/ern.12.97

[34] Kurth, T., Diener, H.C. and Buring, J.E. (2011) Migraine and Cardiovascular Disease in Women and the Role of Aspirin: Subgroup Analyses in the Women's Health Study. Cephalalgia, 31, 1106-1115. https://doi.org/10.1177/0333102411412628

[35] Tana, C., Tafuri, E., Tana, M., Martelletti, P., Negro, A., Affaitati, G., Fabrizio, A., Costantini, R., Mezzetti, A. and Giamberardino, M. (2013) New Insights into the Cardiovascular Risk of Migraine and the Role of White Matter Hyperintensities: Is Gold All That Glitters? The Journal of Headache and Pain, 14, 9.

https://doi.org/10.1186/1129-2377-14-9

[36] Negro, A., D’Alonzo, L. and Martelletti, P. (2010) Chronic Migraine: Comorbidities, Risk Factors, and Rehabilitation. Internal and Emergency Medicine, 5, S13-S19. https://doi.org/10.1007/s11739-010-0457-7 